\title{
Sharing and learning through the Pediatric Cardiac Critical Care Consortium: Moving toward precision care
}

\author{
Peter C. Laussen, MB, BS, FANZCA, FCICM
}

\begin{abstract}
Feature Editor's Introduction-The most recent events of the Coronavirus Disease 2019 pandemic have demonstrated that we all live in a small world and we are all inseparably connected to each other. Sharing of medical knowledge has no borders or national identity. The utmost importance of medical collaboration has become increasingly clear. The importance of such collaboration cannot be overemphasized. A timely and topical Invited Expert Opinion article written by one of the leading specialists in Critical Care Medicine, Peter C. Laussen, is published in the current issue of the Journal. Clearly, a Pediatric Cardiac Critical Care Consortium is the type of collaboration that we should all aspire to emulate.
\end{abstract}

\section{Igor E. Konstantinov, MD, PhD, FRACS}

The Severe Acute Respiratory Syndrome Coronovirus-2 pandemic causing Coronavirus Disease 2019 is dominating all aspects of our professional and personal lives. We are grateful for all of our colleagues across the world who are confronting this illness head on, exposing themselves to risk to save lives, and meeting extreme challenges from limitations in equipment and staffing. Fortunately, the impact of Severe Acute Respiratory Syndrome Coronavirus-2 in the pediatric population has been much smaller than seen in adults, but we remain mindful of the potential vulnerability of patients with congenital heart disease, both to infection and that many time-sensitive procedures have been deferred.

The scale of the Coronavirus Disease 2019 illness has challenged the way we have been organized as a broad medical community, revealing the variability between regions, the disparities in delivery that exist, and our lack of iterative data that allows for meaningful prediction as well as reaction. The challenges of managing the pandemic related to variability in systems, resources, practices, and outcomes are relevant to many fields of medicine, and although I

\footnotetext{
From the Department of Critical Care Medicine, Hospital for Sick Children, Toronto, Canada; and Department of Anesthesia, University of Toronto, Toronto, Canada. Received for publication April 27, 2020; revisions received May 6, 2020; accepted for publication May 8, 2020; available ahead of print June 10, 2020.

Address for reprints: Peter C. Laussen, MB, BS, FANZCA, FCICM, Department of Critical Care Medicine, Hospital for Sick Children, Toronto, 555 University Ave,

Toronto, Ontario, Canada M5G 1X8 (E-mail: peter.laussen@sickkids.ca).

J Thorac Cardiovasc Surg 2021;161:2195-9

0022-5223/\$36.00

Copyright (C) 2020 by The American Association for Thoracic Surgery

https://doi.org/10.1016/j.jtcvs.2020.05.092
}

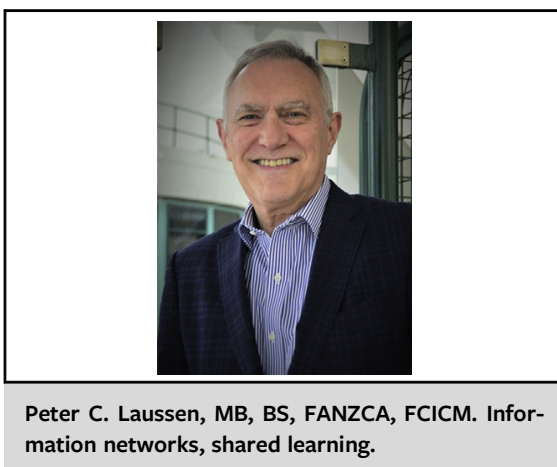

\begin{abstract}
CENTRAL MESSAGE
The PC4 registry demonstrates we can share, learn, and improve outcomes in pediatric cardiac critical care. Individualized pediatric critical care is an aspiration and achievable.
\end{abstract}

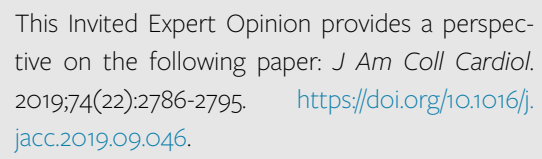

See Commentary on page 2200.

understand we will not see a pandemic in congenital heart disease, it is worthy of reflection in the way our field is organized and provides care. It is fair to state that in large part the congenital heart disease community has become well organized, with considerable efforts made to share and even standardize practices. Our surgical colleagues have led the way with the development of various national and international registries, which have helped standardize nomenclature and dictionaries, develop risk adjustment tools, and collect case, volume, and outcome-specific data for effective benchmarking, all of which have opened up comparative reviews and new research in congenital cardiac surgery. ${ }^{1-3}$ Similar efforts have expanded in other areas, including pediatric cardiac catheterization, ${ }^{4}$ pediatric cardiology (Pediatric Acute Care Cardiology Collaborative), cardiac anesthesia, ${ }^{6}$ and cardiac critical care (Pediatric 
Cardiac Critical Care Consortium [PC4]). ${ }^{7}$ These efforts continue to evolve with increasing efforts to link databases and integrate and involve parents and patients (such as through the Cardiac Networks United). ${ }^{8}$

Besides providing a window into clinical activities and some outcomes, do these activities change and improve practice? Can they be a reliable benchmark against which performance can be truly adjusted and measured? This is important information for all stakeholders, of course, and increasingly a requirement and mandate for the reporting of institutional and center-related performance to government agencies, insurance providers, and other organizations that seek to rank programs (eg, U.S. News \& World Report) or ensure the provision of high-quality and safe care (eg, The Leapfrog Group). ${ }^{9}$ To be effective, registries need to be iterative and adaptive, and it is in this context that the recent article describing the success of the PC4 is reviewed. ${ }^{10}$

\section{PEDIATRIC CARDIAC CRITICAL CARE CONSORTIUM}

PC4 is a quality improvement collaborative of now more than 50 pediatric cardiac intensive care units (ICUs) across North America. The goal of the registry has been to collect data for timely reporting and to enable transparency and learning between participating hospitals. Data at the time of discharge are entered into a web-based reporting platform, and there are the appropriate governance and audit structures in place to ensure reliable data entry. ${ }^{11}$ Although some automated data extraction is possible, sites generally need to invest in personnel to abstract and enter data. This cost can be a barrier at some centers; therefore, it is important that improvements and the associated cost reductions can be demonstrated to show the return on investment hospital administrators like to see. Given the improvements noted in the report of outcomes from the PC4 collaboration, this should be an easy argument. Of course, whether or not a hospital contributes to the PC4 registry as a metric for ranking between hospitals and programs is also an important driver for adoption.

The transparency of PC4 data is based on contributing sites agreeing to be de-identified in the registry, but these de-identified data are not freely available. It is not an open-access site. Rather, an individual (clinical champion) at each site has access to their site's data and can compare this data with all other contributing sites that are identified. Other access is possible with permission, but only the site data of interest are identified in this circumstance and all other sites remain de-identified. Therefore, contributing sites must have a well-established quality assurance process and agree to use the data confidentially and internally to drive improvement. The learning comes when sites are prepared to share their data, to communicate and discuss why centers are performing well, and compare management strategies. Through this process, variation in practices can be identified, but it is important to note that the registry does not provide information as to cause.

The impact of PC4 was recently reported by Gaies and colleagues, ${ }^{10}$ who analyzed the adjusted rates per pediatric cardiac critical care admission or hospitalization for postoperative categoric outcome metrics of mortality and complications, and continuous metrics of length of stay and duration of mechanical ventilation. Over the period of August 2014 through June 2018, 18 hospitals (19,600 hospital admissions) were included, with each having at least 30 months of data entered into the registry. Each hospital had an initial "exposure" period of 2 years in the collaborative to establish data accrual and a baseline for the primary analysis, and a "postexposure" period ranging from 6 to 20 months. In doing so, the authors were able to account for bias from secular trends or by including hospitals with better outcomes over the time frame. To test for a potential "Hawthorne effect" by joining the collaborative and improvements during the baseline exposure period, a trend test by month during the first 2 years of participation was performed. Their careful methodology enabled a more robust assessment as to whether inclusion in the PC4 collaborative was actually associated with the improvement in quality outcomes, as seems to have been the case.

The important findings were a significant reduction in (1) postoperative mortality $(-22 \%$ relative change from mean $2.7 \%$ to $2.1 \%$ ); (2) in-hospital mortality ( $-24 \%$ relative change from mean $3.3 \%$ to $2.5 \%$ ); (3) major complications ( $-12 \%$ relative change from mean $11.5 \%$ to $10.1 \%$ ); (4) cardiac intensive care length of stay $(-5 \%$ relative change from mean 7.7 days to 7.3 days); and (5) duration of mechanical ventilation $(-13 \%$ relative change from mean 70.6 to 61.3 hours). These are all important improvements and from the analysis can be attributed to a large extent simply through participation in the collaborative. The question is why participation alone was sufficient, particularly because it is not possible to ascribe any causal relationships and there were no PC4-directed interventions. The early adopters and collaborators may reflect already highperforming centers with robust and iterative quality systems in place, such as regular review of performance across their program, that are self-critical and importantly possess a questioning attitude and culture that can drive change and adapt quickly. It will be important to continue to follow sustained improvement in these areas as more hospitals contribute data.

The PC4 data site is an interactive series of dashboards for a range of iterative clinical and operational metrics. The database does not tell a site what to do, but does highlight areas that are problems as well as areas of success. It is possible for a site to see where hot spots exist, how they compare, and to sometimes be reassured that the problem a particular site is facing is also a challenge at other sites. 
We all like to think we have the right approach and systems in place, practicing a certain way, and the value of PC4 is that it allows sites to confront these notions, biases, and comfort zones. Participation in PC4 means you can't hide from the comparative data, and if not doing well in some areas, to reach out to those performing better. There is no judgment, rather the main benefit would seem to be to drive behaviors that lead to collaboration and improvement.

Of course, the PC4 registry is an important database for research, and a number of reports have been generated. ${ }^{12-19}$ Gaies and colleagues ${ }^{10}$ did not demonstrate a change in the frequency of cardiac arrest over the 18 sites in their report, and this has spurred collaborative efforts to implement cardiac arrest prevention measures across the collaborative; this is an excellent example of the learning opportunities.

\section{UNIQUE CHALLENGES}

Patients with congenital heart disease pose unique challenges related to the breadth of complex cardiac malformations and associated pathophysiology. Pediatric cardiac critical care as a subspecialty within the field of pediatric intensive care arose because of these unique challenges, and in parallel with the advances in surgical techniques, catheter-based interventions, and medical strategies for children with congenital and acquired heart disease. At the core of the Heart Center model now used in many pediatric cardiology and cardiac surgery programs was the recognition that to improve outcomes, an interdisciplinary approach to care was needed, developing consistent practices, transfer of information, and an understanding of the approaches to management.

A recent study published in the Journal used the PC4 data to further explore potential factors contributing to mortality after congenital heart surgery. ${ }^{20}$ Typically, patient factors including age, weight, prematurity, chromosomal anomalies/syndromes, and risk category come out in models as significant factors contributing to mortality. There is little that is modifiable in these population- and patient-related factors, other than perhaps controlling the time of delivery. Surgery-related factors including experience, technical outcomes, bypass and crossclamp times, and hospital factors such as case volume are also often entered into models to determine relationship with mortality. Some of these are modifiable.

Using the statistical approach of partitioned variances, Pasquali and colleagues ${ }^{20}$ were able to demonstrate from PC4 data that the typical patient- and population-based factors included in congenital heart surgery risk models explain only a small portion of total variation in mortality. In other words, there are "unmeasured" factors and data that we need to include in models. To make the next-level improvement, it is essential to look at all aspects of patient management as well as surgical technical performance. The question is, what are these variables?

\section{MODIFIABLE RISK}

We need to understand the contribution of our management and decisions in pediatric cardiac critical care to patient outcome, harm, and mortality, and therefore the truly modifiable risks in critical care practices. This is unknown and very likely one of the "unmeasured" factors mentioned earlier. The use of extracorporeal life support and renal replacement therapy is associated with mortality risk after congenital heart surgery, as is multisystem organ failure and sepsis; these are all targets for improvement. Often it is hard to define one specific event, and rather it is more appropriate to look at the "dose" of care," that is, the period of exposure, such as the duration of time or frequency the patient was relatively hypotensive, had a low coronary perfusion pressure, or had too much afterload, tachycardia, and myocardial oxygen demand. It is important variables such as these that become part of the institutional memory, that a decision tree or matrix is captured, so that the potential factors and management options are understood and potentially modified the next time a similar circumstance arises.

We manage individual patients, rather than just a population of patients. As a simple yet important example, knowing the physiologic phenotype, and in particular developing iterative targets or boundaries for physiologic signals, is important. Currently, the "normal" range of a physiologic signal is derived from standard nomograms, although it is important to appreciate that these have been developed from healthy children and may not apply at all to the patients we manage after cardiac surgery. The physiologic phenotype will vary by age and weight, but also by diagnosis and procedure, ${ }^{21,22}$ by the treatments we deliver, by clinician preference, and by time (ie, postoperative day 1 vs subsequent days). Therefore, it is important to understand that the targets and boundaries for physiologic signals are dynamic, and we should develop both population-based and individual data to know what the targets for a physiologic variable should be for any point in time.

\section{RESCUE AND PREDICT}

We all measure certain events within our critical care units to measure quality and safety, and usually as a reflection of overall performance. To understand performance, however, we need to examine more closely our ability to be predictive and prevent events. Indeed, we can rescue patients effectively in our ICUs; however, the "failure to rescue" rate is not the only metric we should be measured against. Our "failure to predict" is also an important performance metric because it speaks to our judgment, but is much harder to measure. 
Throughout a patient's journey, we overlay a network of guidelines, protocols, monitors, and devices, and yet our decision-making often follows variable and different treatment nodes. A reason for this may be because we are not good at standardizing care, but I think this is too simplistic. Rather, we are managing individual patients with variability in biology and physiology, and we have to expect this and adapt to uncertainty. Practice and decisions must be iterative and flexible, and will therefore vary. What we don't do well though is capture individual judgments and decision making (why we chose to do, or not do, a certain action).

\section{INDIVIDUALIZED CRITICAL CARE}

Precision or individualized critical care means that we tailor management to the patient, and it is based on multiple and integrated data inputs. The PC4 database is an important source of data in this regard because it provides prognostic enrichment that focuses on the result or outcomes of treatment. ${ }^{23}$ There is an important second component, however, which is the predictive enrichment from data that is based on the biological responses to illness and treatment, and therefore their physiologic state.

It is noteworthy that predictive data analytics are used in less than $20 \%$ of pediatric cardiac ICUs. ${ }^{24}$ In this era of ubiquitous electronic healthcare records and emerging methods for capturing high-frequency physiologic data, ${ }^{25}$ this is a deficiency. Time-series continuous physiologic data generated from patients in the operating room, ICU, and ward settings must be captured and stored permanently; analysis will allow better understanding of physiologic states and risks for an event within that state. Ideally, a physiologic databank for predictive enrichment could be established that complements the prognostic enrichment available in the PC4 database.

An important component that is not captured in registries is our macrocognitive processes, that is, the decisions we make and the underlying processes driving these decisions. This understanding would require various human factors engineering experiments, such as cognitive task analysis. In one study, for example, the primary macrocognitive process used by pediatric critical care physicians centered around sense making and understanding the problem(s), while the primary macrocognitive process used by pediatric critical care nurses in the same unit focused more on managing complexity. ${ }^{26}$ How we make decisions is critical and the subject of an expanding amount of research. Unfortunately, there is no clear method to capture or evaluate them (other than debriefing an adverse event or outcome of a particular patient). We can try and infer decisions by some of the changes that are found in the electronic health record, such as when a drug was increased or decreased in response to a hemodynamic change, when fluid was administered, or how frequently laboratory tests are performed, but these are imprecise.

\section{CONCLUSIONS}

Developing individualized pediatric critical care is an aspiration and achievable. It starts with building robust, relevant, and relatable prognostic enrichment databases, such as PC4. The developers of PC4 are to be congratulated on their vision and implementation. This platform can be further enriched by integrating datasets, either centralized or in a linked federated system. This will require a change in mindset over data collection and consent, data architecture and solving bottlenecks, data access and governance, and ethical use and privacy, to name some of the challenges. These can be overcome and should not be barriers. The PC4 registry demonstrates we can learn and improve through data collection and participation. To understand the modifiable risks for patients, we need additional open-source data to enable predictive enrichment, such as continuous physiologic data, as well as the variable and dynamic decisionmaking processes we use.

\section{Conflict of Interest Statement}

The author reported no conflicts of interest.

The Journal policy requires editors and reviewers to disclose conflicts of interest and to decline handling or reviewing manuscripts for which they may have a conflict of interest. The editors and reviewers of this article have no conflicts of interest.

\section{References}

1. Vener DF, Gaies M, Jacobs JP, Pasquali SK. Clinical databases and registries in congenital and pediatric cardiac surgery, cardiology, critical care, and anesthesiology worldwide. World J Pediatr Congenit Heart Surg. 2017;8:77-87.

2. Jacobs JP. Databases for assessing the outcomes of the treatment of patients with congenital and pediatric cardiac disease: the perspective of cardiac surgery. In: Barach PR, Jacobs JP, Lipshultz SE, Laussen PC, eds. Pediatric and Congenital Cardiac Care: Volume 1 Outcomes Analysis. London: Springer-Verlag; 2015:77-126.

3. Calderone C, Poynter JA, Williams WG. The academic database: lessons learned from the Congenital Heart Surgeons' Society data center. In: Barach PR, Jacobs JP, Lipshultz SE, Laussen PC, eds. Pediatric and Congenital Cardiac Care: Volume 1 Outcomes Analysis. London: Springer-Verlag; 2015:171-84.

4. Kanter JP, Bergersen L, Coombs S, Forbes TJ, Everett AD, Martin GR. Pediatric cardiac catheterization databases. In: Barach PR, Jacobs JP, Lipshultz SE, Laussen PC, eds. Pediatric and Congenital Cardiac Care: Volume 1 Outcomes Analysis. London: Springer-Verlag; 2015:243-58.

5. Kipps AK, Cassidy SC, Strohacker CM, Graupe M, Bates KE, McLellan MC, et al. Collective quality improvement in the paediatric cardiology acute care unit: establishment of the Pediatric Acute Care Cardiology Collaborative (PAC3). Cardiol Young. 2018;28:1019-23.

6. Vener DF, Guzzetta N, Jacobs JP, Williams GD. Development and implementation of a new data registry in congenital cardiac anesthesia. Ann Thorac Surg. 2012;94:2159-65.

7. Gaies M, Cooper DS, Tabbutt S, Ghanayem N, Chanani NK, Costello JM, et al. Collaborative quality improvement in the cardiac intensive care unit: development of the paediatric cardiac critical care consortium (PC4). Cardiol Young. 2015;25:951-7.

8. Gaies M, Anderson J, Kipps A, Lorts A, Madsen N, Marino B, et al. Cardiac Networks United: an integrated paediatric and congenital cardiovascular research and improvement network. Cardiol Young. 2019;29:111-8.

9. The Leapfrog Group. Available at: https://www.leapfroggroup.org/. Accessed April 24, 2020.

10. Gaies M, Pasquali SK, Banerjee M, Dimick JB, Birkmeyer JD, Zhang W, et al. Improvement in pediatric cardiac surgical outcomes through interhospital collaboration. J Am Coll Cardiol. 2019;74:2786-95. 
11. Gaies M, Donohue JE, Willis GM, Kennedy AT, Butcher J, Scheurer MA, et al. Data integrity of the pediatric cardiac critical care consortium (PC4) clinical registry. Cardiol Young. 2016;26:1090-6.

12. Alten JA, Rhodes LA, Tabbutt S, Cooper DS, Graham EM, Ghanayem N, et al. Perioperative feeding management of neonates with CHD: analysis of the pediatric cardiac critical care consortium (PC4) registry. Cardiol Young. 2015;25: 1593-601.

13. Benneyworth BD, Mastropietro CW, Graham EM, Klugman G, Costello JM, Zhang W, et al. Variation in extubation failure rates after neonatal congenital heart surgery across pediatric cardiac critical care consortium hospitals. $J$ Thorac Cardiovasc Surg. 2017;153:1519-26.

14. Alten JA, Klugman D, Raymond TT, Cooper DS, Donohue JE, Zhang W, et al. Epidemiology and outcomes of cardiac arrest in pediatric cardiac ICUs. Pediatr Crit Care Med. 2017;18:935-43.

15. Romans RA, Schwartz SM, Costello JM, Chanani NK, Prodhan P, Gazit AZ, et al. Epidemiology of noninvasive ventilation in pediatric cardiac ICUs. Pediatr Crit Care Med. 2017;18:949-57.

16. Gaies M, Werho DK, Zhang W, Donohue JE, Tabbutt S, Ghanayem NS, et al. Duration of postoperative mechanical ventilation as a quality metric for pediatric cardiac surgical programs. Ann Thorac Surg. 2018;105:615-21.

17. Alten JA, Rahman AKMF, Zaccagni HJ, Shin A, Cooper DS, Blinder JJ, et al. The epidemiology of healthcare-associated infections in pediatric cardiac intensive care units. Pediatr Infect Dis J. 2018;37:768-72.

18. Smith AH, Anand V, Banerjee M, Bates KE, Brunetti MA, Cooper DS, et al. Variation in case-mix adjusted unplanned pediatric cardiac ICU readmission rates. Crit Care Med. 2018;46:e1175-82.
19. Rooney SR, Donohue JE, Bush LB, Zhang W, Banerjee M, Pasquali SK, et al Extubation failure rates after pediatric cardiac surgery vary across hospitals. $\mathrm{Pe}$ diatr Crit Care Med. 2019;20:450-6.

20. Pasquali SK, Gaies M, Banerjee M, Zhang W, Donohue J, Russell J, et al. The quest for precision medicine: unmeasured patient factors and mortality after congenital heart surgery. Ann Thorac Surg. 2019;108:1889-94.

21. Eytan D, Goodwin AJ, Greer R, Guerguerian AM, Mazwi M, Laussen PC Distributions and behavior of vital signs in critically ill children by admission diagnosis. Pediatr Crit Care Med. 2018;19:115-24.

22. Eytan D, Goodwin AJ, Greer R, Guerguerian AM, Laussen PC. Heart rate and blood pressure centile curves and distributions by age of hospitalized critically ill children. Front Pediatr. 2017;17:52.

23. Wong HR, Atkinson SJ, Cvijanovich NZ, Anas N, Allen GL, Thomas NJ, et al Combining prognostic and predictive enrichment strategies to identify children with septic shock responsive to corticosteroids. Crit Care Med. 2016;44 e1000-3.

24. Horak RV, Alexander PM, Amirnovin R, Klein MJ, Bronicki RA, Markovitz BP et al. Pediatric cardiac intensive care distribution, service delivery and staffing in the United States in 2018. Pediatr Crit Care Med. 2020 [In press].

25. Goodwin A, Eytan D, Greer R, Mazwi M, Thommandram A, Goodfellow SD, et al. A practical approach to storage and retrieval of high frequency physiological signals. Physiol Meas. 2020;41:035008.

26. Lin YL, Guerguerian AM, Tomasi J, Laussen P, Trbovich P. Usability of data integration and visualization software for multidisciplinary pediatric intensive care: a human factors approach to assessing technology. BMC Med Inform Decis Mak. 2017;17:1-19. 